\title{
Guest editorial introduction to the special issue on "advanced signal processing techniques and telecommunications network infrastructures for smart grid analysis, monitoring, and management"
}

\author{
Antonio Bracale ${ }^{1 *}$, Julio Barros ${ }^{2}$, Angela Sara Cacciapuoti ${ }^{3}$, Gary Chang ${ }^{4}$ and Emiliano Dall'Anese ${ }^{5}$
}

Electrical power systems are undergoing a radical change in structure, components, and operational paradigms, and are progressively approaching the new concept of smart grids (SGs). Future power distribution systems will be characterized by the simultaneous presence of various distributed resources, such as renewable energy systems (i.e., photovoltaic power plant and wind farms), storage systems, and controllable/non-controllable loads. Control and optimization architectures will enable network-wide coordination of these grid components in order to improve system efficiency and reliability and to limit greenhouse gas emissions. In this context, the energy flows will be bidirectional from large power plants to end users and vice versa; producers and consumers will continuously interact at different voltage levels to determine in advance the requests of loads and to adapt the production and demand for electricity flexibly and efficiently also taking into account the presence of storage systems.

This evolution of power distribution networks involves also an increasingly complex and performing Information and Communication Technology (ICT) infrastructure. An increasing and continuous flow of information will be exchanged among the various levels of such systems in order to ensure an optimized operation of the network and an efficient management of distributed resources. Then, SGs operate with two-way flows of both electricity and information. The necessary communication resources heavily depend on the choices related to the required signal processing for analysis, monitoring, and management of the network.

\footnotetext{
* Correspondence: antonio.bracale@uniparthenope.it

${ }^{1}$ Department of Engineering, University of Naples Parthenope, Centro

Direzionale di Napoli, Is. C4, 80143 Naples, Italy

Full list of author information is available at the end of the article
}

Many research contributions have been published recently in the relevant literature, covering the innovative topics associated with this new concept of functional power systems. However, few papers have addressed the problems inherent to the study of the advanced signal processing techniques and telecommunications network infrastructures which are needed for the modern SGs. This is the reason for this special issue.

There are many aspects where signal processing plays a crucial role for planning and operation of SGs. This special issue focuses on some of them, addressing in particular the development of new, advanced, signal processing methods for studying the characteristics of highly non-stationary waveforms involved in the analysis, monitoring and management of the electrical quantities at nodes/branches of the smart grids.

Our call for papers attracted numerous submissions worldwide. In response to the call for papers for this special issue, after the review process, 12 were accepted for publication, with co-authors from Asia, Europe, South America, and the USA These papers are briefly described in the following.

In [1], the authors use higher-order statistics-based feature extraction and regression algorithms implemented in artificial neural networks (ANNs) to classify power quality disturbances. The novel aspect of the method proposed is the use of a feature vector based on the combination of time and frequency domain higher-order statistic coefficients obtained from the samples of the input signal. Seven regression algorithms implemented in ANNs are compared for classification of different power quality disturbances: stationary harmonic distortion, time-varying harmonics, oscillatory transients, impulsive transients, interruptions, voltage swells, and voltage sags 
and voltage sags plus oscillatory transients, with the method based on radial basis networks, generalized regression, and multilayer perception showing the best performance. In [2], the authors study the noise, the channel response, and the input impedance of the power line network in different scenarios (rural, semi-urban, and urban), providing an estimation of the data rates obtained in each case. In addition, the paper also studies the simultaneous use of the three-phase conductors in low-voltage distribution networks for multiple-input multiple-output communications, in order to improve the performance of the single-input single-output communication systems. In paper [3], the enhanced power system electromechanical oscillation estimation via subspace identification is proposed. Singular value-based method is adopted to improve the computation efficiency for determining the model order of the estimated system and increase the solution accuracy of the estimates. A mode matching method based on the characteristics of accurate mode shape estimates is then proposed to ensure the correctness of the estimates. Simulation results validate the feasibility of the proposed methods. Paper [4] is focused on the problem that, in the future, a significant portion of electricity demand will be somewhat flexible and, accordingly, may be responsive to changes in electricity prices. In particular, the study of the collusion between generators and loads that can manipulate this market is studied, and a method aimed to learn how to deter such collusion is proposed. In [5], a data processing network for an in-house low-voltage smart grid is considered. The aim of the paper is the proposal of a high-rate measurement architecture for data processing, monitoring, and management in a smart grid characterized by real-time measurements and sophisticated control integrating fluctuating renewable power sources and/or prosumers (such as electrical vehicles and storage systems).

Papers [6-8] are focused on different aspects of power quality in smart grids. In particular, the problem of new hardware with adequate computational capability and time intensive, cost-ineffective manual implementations in advanced power quality metering algorithms is studied in [6]. In fact, a model-based design approach to rapidly implement power quality metering algorithms is proposed that is able to focus on the design, validation, and testing stages while skipping over implementation issues. In [7], a new analytical estimator for light flicker in frequency domain is presented. The proposed estimator is applied to numerous numerical case studies showing higher accuracy than the classical IEC flickermeter and can be included in signal processing tools for interharmonic penetration studies due to renewable energy sources in future smart grids. In [8], power quality level reduction caused by dispersed renewable generation connected to the grid through static converters is considered. In particular, advanced parametric methods for assessing waveform distortions (such as Prony and ESPRIT, and some hybrid methods) are critically compared on the basis of their accuracy and the computational effort required. Recent developments associated with signal processing applied to power system analysis in terms of characterization and diagnostics are reported in [9] where some techniques applied to power fluctuations are reviewed and their characteristics and applications discussed.

In [10], the error probability analyses are performed for a hybrid direct sequence modulation with fast frequency hopping (DS/FFH) system over standard Gaussian and fading-type channels, progressively including the effects from wide- and partial-band jamming, multiuser interference, and varying degrees of Rayleigh and Rician fading. In addition, an optimization approach is formulated that minimizes the bit error performance of a hybrid DS/FFH communication system and solves for the resulting system design parameters. In article [11], the problem of distribution system state estimation for the management and control in smart grids is studied. In particular, a simple technique, which exploits the particular formulation of the branch current estimators, is proposed. Paper [12] presents a distributed approach to optimal power flow in an electrical network, suitable for application in a future smart grid scenario where access to resource and control is decentralized.

\section{Competing interests}

The authors declare that they have no competing interests.

\section{Acknowledgments}

The guest editors of this special issue wish to thank all the contributing authors for submitting high-quality papers to this special issue. We would also like to thank all the reviewers for their thorough and valuable evaluation of the papers within the short stipulated time. Their careful reviews and valuable comments helped us select the papers as well as improve the quality of this special issue. We would like to thank the whole Editorial Board for their support. Finally, we owe a debt of gratitude to the whole editorial and publication staff of EURASIP Journal on Advances in Signal Processing that provided us assistance and continuous support throughout the whole process.

\section{Author details}

${ }^{1}$ Department of Engineering, University of Naples Parthenope, Centro Direzionale di Napoli, Is. C4, 80143 Naples, Italy. ${ }^{2}$ Electronics and Computers Department, University of Cantabria, Santander, Spain. ${ }^{3}$ Department of Electrical Engineering and Information Technology (DIETI), University of Naples Federico II, Naples, Italy. ${ }^{4}$ Department of Electrical Engineering, National Chung Cheng University, Chia-yi, Taiwan, Republic of China. ${ }^{5}$ National Renewable Energy, Laboratory Power Systems Engineering Center, Golden, CO, USA.

Received: 4 May 2015 Accepted: 4 May 2015

Published online: 10 June 2015

\section{References}

1. JC Palomares-Salas, JJ González de la Rosa, JM Sierra-Fernández, A Agüera-Pérez, HOS network-based classification of power quality events via regression algorithms. EURASIP J. Adv. Signal Process. 2015(1), 1-11 (2015) 
2. JA Cortés, A Sanz, P Estopinán, JI García, Analysis of narrowband power line communication channels for advanced metering infrastructure. EURASIP J. Adv. Signal Process. 2015(1), 1-13 (2015)

3. S Ding, $\mathrm{H}$ Huang, Improvements for electromechanical oscillation mode estimation via subspace identification methods. EURASIP J. Adv. Signal Process. (2015)

4. Y Shan, J Raghuram, G Kesidis, DJ Miller, A Scaglione, J Rowe, K Levitt, Generation bidding game with potentially false attestation of flexible demand. EURASIP J. Adv. Signal Process. 2015(1), 1-11 (2015)

5. H Maaß, HK Cakmak, F Bach, R Mikut, A Harrabi, W Süß, W Jakob, S Karl-Uwe, UG Kühnapfel, V Hagenmeyer, Data processing of high rate low voltage distribution grid recordings for smart grid monitoring and analysis. EURASIP J. Adv. Signal Process. 2015(1), 1-21 (2015)

6. K Kołek, K Piątek, Rapid algorithm prototyping and implementation for power quality measurement. EURASIP J. Adv. Signal Process. 2015(1), 1-12 (2015)

7. L Feola, R Langella, A Testa, A new frequency approach for light flicker evaluation in electric power systems. EURASIP J. Adv. Signal Process. 2015(1), 1-12 (2015)

8. L Alfieri, Some advanced parametric methods for assessing waveform distortion in a smart grid with renewable generation. EURASIP J. Adv. Signal Process. 2015(1), 1-16 (2015)

9. L Rodrigues Manso, CA Duque, PF Ribeiro, Smart signal processing for an evolving electric grid. EURASIP J. Adv. Signal Process. (2015)

10. MM Olama, M Xiao, SM Killough, T Kuruganti, SF Smith, SM Djouadi, Analysis, optimization, and implementation of a hybrid DS/FFH spread-spectrum technique for smart grid communications. EURASIP J. Adv. Signal Process. 2015(1), 1-18 (2015)

11. C Muscas, M Pau, PA Pegoraro, S Sulis, An efficient method to include equality constraints in branch current distribution system state estimation. EURASIP J. Adv. Signal Process. 2015(1), 1-11 (2015)

12. T Erseghe, A distributed approach to the OPF problem. EURASIP J. Adv. Signal Process. (2015)

\section{Submit your manuscript to a SpringerOpen ${ }^{\circ}$} journal and benefit from:

- Convenient online submission

- Rigorous peer review

- Immediate publication on acceptance

- Open access: articles freely available online

- High visibility within the field

- Retaining the copyright to your article 